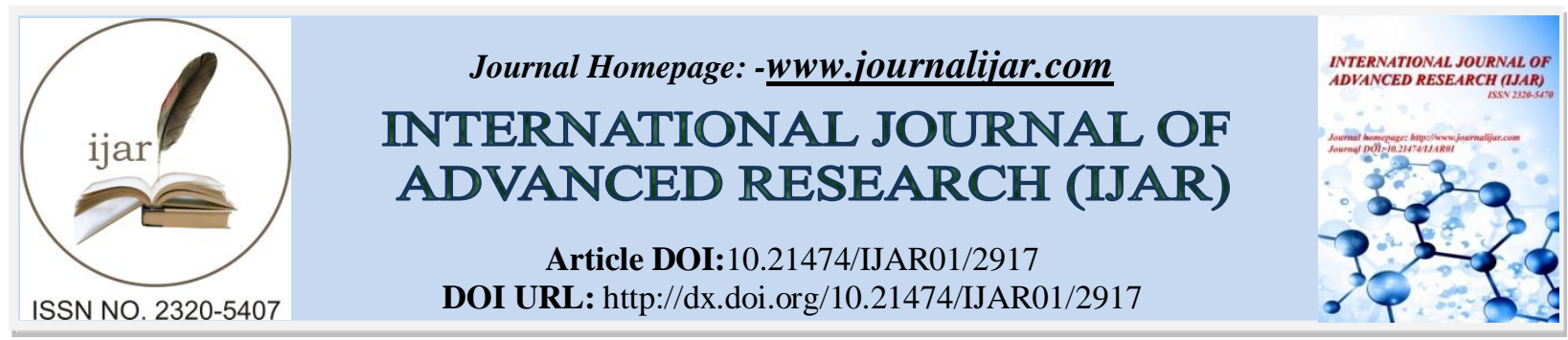

RESEARCH ARTICLE

\title{
CELIAC DISEASE AWARENESS AMONG PHYSICIANS IN SAUDI ARABIA: AN EPIDEMIOLOGICAL STUDY.
}

\section{Mohammed A. Aljebreen ${ }^{1}$, Abdallah F. Alfozan ${ }^{1}$, , Sayyaf S. Alnasser ${ }^{1}$, Moath M. Fairaq ${ }^{1}$, Salem K.} Albalawi ${ }^{1}$, Mohammed E. Alqahtani ${ }^{1}$ and Abdulrahman M. Aljebreen ${ }^{2}$.

1. Department of Medicine, College of Medicine, King Saud University, Riyadh, Saudi Arabia.

2. Division of Gastroenterology, King Khalid University Hospital, King Saud University, Riyadh, Saudi Arabia.

\section{Manuscript Info}

\section{Manuscript History}

Received: 24 November 2016

Final Accepted: 25 December 2016

Published: January 2017

Key words:-

Celiac disease, Awareness, and

Epidemiological survey.

\section{Abstract}

Background: Although Celiac disease (CD) prevalence has progressively increased in the last 20 years worldwide, affecting as high as $2.5 \%$ of population in Saudi Arabia, the level of physician's knowledge of this disease has not been reported.

Objective: The aim of this study is to assess the knowledge of CD among Saudi physicians who face this common health problem in their clinics.

Methodology: We conducted this cross-sectional survey of 286 consultant physicians within 6 medical subspecialties and were based in 6 different medical centers in Riyadh, Saudi Arabia in the period from October 2013 to February 2014. A special questionnaire to test physician's knowledge of celiac disease was designed based on the relevant literature, and it was validated through a pilot study prior to data collection.

Results: In the physician survey only 131 (46\%) physicians returned the questionnaires.The majority of our respondents had more than 10 years of practice $(49.62 \%)$. There were several significant findings from the participants' response to the questionnaire. For example, Celiac disease is common in the west as in Saudi Arabia but only 23 (17.56\%) out of 131 were not aware of this fact. Furthermore, 29 (22.14\%) out of the 131 physicians did not know that intestinal biopsy is a mandatory test to confirm celiac disease.

Conclusion:There isa significant percentage of physicians who did not have enough knowledge about CD.Thismight affect the early detection of the disease and the patients' quality of life negatively.

Copy Right, IJAR, 2016,. All rights reserved.

\section{Introduction:-}

Celiac disease (CD) is a chronic systemic immune-mediated disease induced by dietary gluten proteins present in wheat, rye and barley. $\mathrm{CD}$ is an inflammatory disorder of the upper small intestine, most probably caused by an abnormal immune reaction to wheat gliadin ${ }^{(1)}$. The Celiac disease (CD) prevalence has progressively increased in the last 20 years and, recently, it was proposed that it might affect 0.6 to $1.0 \%$ of population worldwide, and as high as 
$2.5 \%$ in Saudi Arabia ${ }^{(2-7)}$. However, the lack of physician's awareness of celiac disease clinical features, associations, diagnosis treatment and complications may negatively affects their care. The high prevalence of celiac disease makes the early diagnosis of the disease of high importance. The association between the knowledge of the physicians about certain information in celiac disease and the delay of diagnosis and treatment is becoming more evident. The aim of this study is to detect the awareness of the CD disease among primary care physicians, internists, hematologists, endocrinologists, pediatricians and gastroenterologists at Riyadh, which might give us an idea about the delay in diagnosis and treatment plans of celiac disease in Saudi Arabia.

The rationale of this study was that the lack of knowledge of this common disease might delay the diagnosis and cause many serious complications, which could easily be prevented. We believe the information obtained would help to design and conduct educational and training program for involved physician about the celiac disease in the future.

\section{Materials and Methods:-}

This is a cross-sectional survey of 286 physicians which was conducted Riyadh, Saudi Arabia from October 2013 to February 2014 among 6 medical subspecialties who face this CD commonly on their outpatient clinics. This group of physicians included: primary care physicians, gastroenterologists, internists, endocrinologists, hematologists and pediatricians who were based in 6 different medical centers in Riyadh. A special questionnaire to test physician's knowledge of celiac disease was designed based on previous studies and it was validated among 10 physicians prior to starting the study. Hard copies of this questionnaire were handed to a total of 286 physicians, where only 131 physicians have responded. This questionnaire composed of 16 self-administered English questions. The questionnaires asked physicians to choose the correct answer in each of the following topics: etiology, age at onset of symptoms, clinical features, associated diseases, complications of celiac disease, and the diagnosis and management of the celiac disease. There were 3 to 7 options in each of these categories, including some incorrect options and the choice of "I don't know".

We estimate the expected frequency will be $11 \%$ that we took from a previous research done in 2005 in USA under the title (physician awareness of celiac disease). Our confidence limits will be $5 \%$ with a worst expected percent about $6 \%$, Our confidence level will be $99 \%$. We added $10 \%$ non-responsive estimation to our sample size. The Data was entered on Microsoft Excel and checked by two members of the team. Then the data was sent to a statistician, for analyses using The Statistics and Data Analysis Program (Stata) 12.1 version. The Data collected from the questionnaires was divided according to the variables associated to the physicians' awareness about celiac disease (Gender, age, specialty, hospital were the physician works, years of practice).

\section{Results:-}

In the physician survey only $131(46 \%)$ physicians (110 (83.97\%) male and 21 females (16.03\%)) returned the questionnaires. 46 (35.11\%) of our target physicians were between the age group of 30-40 years old.From the years of practice, the majority of our respondents had more than 10 years of practice 65 (49.62\%), followed by 35 $(26.72 \%)$ who had $1-5$ years of practice ${ }^{[\text {Table } 1]}$. but only $66(50.38 \%)$ had ever diagnosed a patient with celiac disease.

Table 1:-years of practice of the physicians that were included in the study, Riyadh, 2014.

\begin{tabular}{|c|c|c|}
\hline \multicolumn{2}{|c|}{} \\
\hline Years Of practice: & Number & Percentage \\
\hline$<1$ year & 5 & 26.82 \\
\hline $1-5$ & 35 & 19.85 \\
\hline $6-10$ & 26 & 49.62 \\
\hline$>10$ years & 65 & $100 \%$ \\
\hline Total & 131 & \\
\hline
\end{tabular}

The 16 questions which assessed the awareness of physicians attending at: King Khalid University Hospital (KKUH), king Saud Medical City (KSMC), King Abdulaziz University Hospital (KAUH), Dallah hospital, AlHabeeb medical centers and some other medical centers. The highest respondents we got was 57 (43.51\%) from King Saud Medical City (KSMC), followed by 30 (22.90\%) from Al-Habeeb Medical Centers ${ }^{\text {[graph } 1] .}$ 


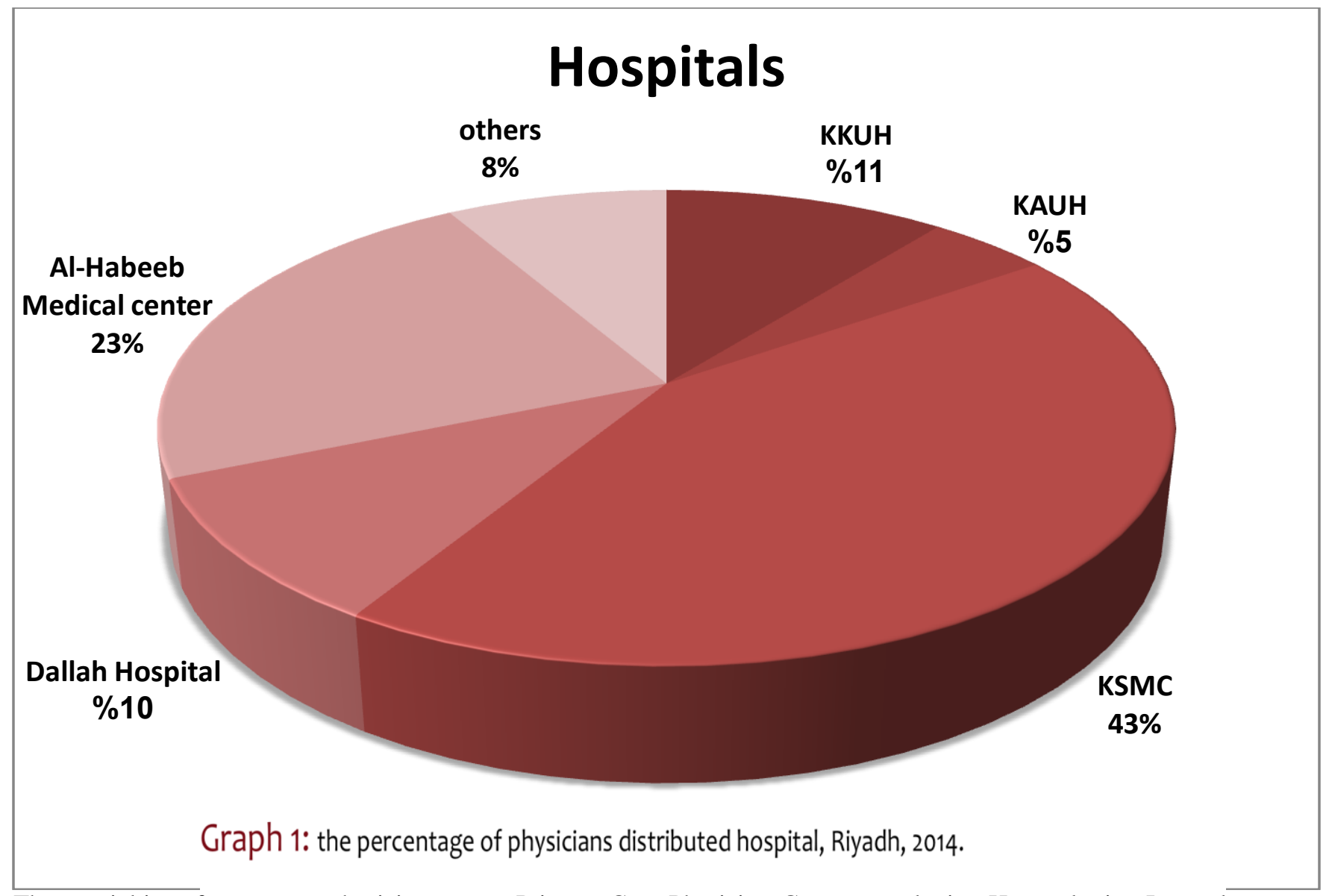

The specialties of our target physicians were: Primary Care Physician Gastroenterologist, Hematologist, Internal Medicine, Endocrinologist and Pediatrician. The highest respondents we got were 43 (32.82\%) pediatricians, followed by $31(23.66 \%)$ physicians from internal medicine ${ }^{\text {[table } 2] .}$

Table 2:- the number and percentage of physicians' specialties that were included in the study, Riyadh, 2014.

\begin{tabular}{|c|c|c|}
\hline Specialty & Number & Percentage \\
\hline Pediatrician & 43 & $32.82 \%$ \\
\hline Internal Medicine & 31 & $23.66 \%$ \\
\hline Primary Care Physician & 24 & $18.32 \%$ \\
\hline Gastroenterologist & 19 & $14.50 \%$ \\
\hline Endocrinologist & 13 & $9.92 \%$ \\
\hline Hematologist & 1 & $0.76 \%$ \\
\hline Total & 131 & $100 \%$ \\
\hline
\end{tabular}

The results of physician questionnaires are summarized in [Table 3].

Table 3:- the questions and correct answers of the questionnaire with the number and percentage of the physicians who answered them correctly, Riyadh, 2014.

\begin{tabular}{|l|l|}
\hline Survey questions & $\begin{array}{l}\text { Physician Awareness } \\
(\%)\end{array}$ \\
\hline Wheat productsCeliac disease is an intolerance to & $118(90.08 \%)$ \\
\hline Celiac disease is affecting patients at any age & $84(64.12 \%)$ \\
\hline Celiac disease is not common in the west compared to Saudi Arabia & $\%) 23(17.56$ \\
\hline Bleeding of rectum is not one of the most common symptoms of Celiac disease & $117(89.31 \%)$ \\
\hline Cough is not related to Celiac disease & $60(45.80 \%)$ \\
\hline Asthma is not related to celiac disease & $43(32.82 \%)$ \\
\hline
\end{tabular}




\begin{tabular}{|l|l|}
\hline Celiac disease is highly associated with diabetes type1 more than type2 & $94(71.76 \%)$ \\
\hline Colon cancer is not a complication of Celiac disease & $24(18.32 \%)$ \\
\hline Intestinal biopsy is a mandatory test to confirm celiac disease & $102(77.86 \%)$ \\
\hline Anti-tissue transglutaminase antibody (anti-tTG) is the most specific celiac antibody test & $69(52.67 \%)$ \\
\hline blood tests for gluten autoantibodies are accurate only while on a gluten containing diet \\
\hline $\begin{array}{l}\text { There is no need to do a genetic testing for the family members of a person diagnosed with } \\
\text { celiac disease }\end{array}$ & $60(45.80 \%)$ \\
\hline Gluten-free diet is a first step in the management of the celiac disease patient & $128(97.91 \%)$ \\
\hline The damage of small intestine will be repaired again after the diet & $111(84.73 \%)$ \\
\hline The gluten-free diet should be a lifelong diet & $122(93.13 \%)$ \\
\hline
\end{tabular}

\section{Discussion:-}

In this study we investigated the awareness of Celiac disease among physicians, and the study showed that there is inadequate knowledge of Celiac disease among physicians.

Celiac disease (CD) is a chronic systemic immune-mediated disease induced by dietary gluten proteins present in wheat products. $\mathrm{CD}$ is an inflammatory disorder of the upper small intestine, most probably caused by an abnormal immune reaction to wheat gliadin. ${ }^{(1)}$ In the survey 13 physicians $(9.92 \%)$ out the 131 physicians didn't know that Celiac disease is intolerance to wheat products.

The diagnosis of celiac disease requires a intestinal biopsy that shows the characteristic findings of intraepithelial lymphocytosis, intestinal villous atrophy and crypt hyperplasia affecting the lining of the upper small intestine. ${ }^{(8,9)}$ In our survey 29(22.14\%) physician out of the 131 physicians didn't know that intestinal biopsy is a mandatory test to confirm celiac disease.

The Identification of celiac disease is facilitated by widely available serologic tests, the most sensitive antibody tests for the diagnosis of celiac disease are of the IgA class particularly anti-endomysial antibodies, antigliadin antibodies and anti-tissue transglutaminase antibodies ${ }^{(9,10)}$.

The antigliadin antibodies are only sensitive in children younger than 18 months of age, Anti-tissue transglutaminase antibody (anti- tTG) is the most specific celiac antibody test. ${ }^{(10,11)}$ In the survey $62(47.33 \%)$ physician out of the 131 physicians didn't know that Anti-tissue transglutaminase antibody (anti- tTG) is the most specific celiac antibody test.

A range of symptoms, signs and complications may be associated with $\mathrm{CD}$, depending on the degree of intestinal involvement. In the survey we tried to ask our physicians in different ways to test the knowledge of Celiac disease symptoms and signs. The physicians generally knewthat bleeding per rectum is not one of the most common symptoms of Celiac disease. Approximately most of our physicians didn't know that cough, asthma and colon cancer are no related to celiac disease.

Although the prevalence of CD has been considered very low in Saudi Arabia, a recent study has shown a serology prevalence rate of 2.2\% (1 in 45) among healthy students, which might be one of the highest rates of celiac disease in the world. ${ }^{(7)}$ The prevalence of celiac disease among risk groups in Saudi Arabia is $9.5 \%$ in short stature children $^{(13)}$ and $10 \%{ }^{(14)}$ or $8.1 \%{ }^{(15)}$ in Type 1 diabetes children. In our survey more than $80 \%$ of our physicians didn't know that Celiac disease is very common in Saudi Arabia compared to the west. Although most of our physicians knew that Celiac disease is highly associated with diabetes type1 more than type2.

Treatment and follow up of Celiac disease involves a gluten-free diet, which means the elimination of all types of food containing gluten which means the elimination of wheat, barley and rye from their diet ${ }^{(16)}$ Most of patients respond very well to the gluten-free diet and their clinical features decline in days or weeks, though the histology of intestine needs months to recover. ${ }^{(17)}$ Generally $85 \%$ and above of our physicians knew that Gluten-free diet is a first step in the management of the celiac disease patient and should be a lifelong diet and the damage of small intestine will be repaired again after the diet. 
The high prevalence of celiac disease makes the early diagnosis of the disease of high importance. The association between the knowledge of the physicians about certain information in celiac disease and the delay of diagnosis and treatment is becoming more evident. From the previous studies and our study we noticed a lack of physician's awareness of celiac disease clinical features, associations, diagnosis treatment and complications that may negatively affects patients care. These new studies have shown the importance of CD for our health care system. Although, this disease is widely spread, its yet often undiagnosed, mainly because of the lacks of awareness among physicians. ${ }^{(18,19)}$ Most of the recent studies are showing a huge need for increasing awareness of the clinical manifestations of $\mathrm{CD}$, as well as increasing awareness of dietary management plans. ${ }^{(20,21,22)}$

\section{Study Limitations:-}

Short time to conduct the research.

\section{Recommendation:-}

We need to increase the sample size, so it can more representation of Riyadh region physicians in addition once we have more data, we need to compare the awareness of the gastroenterologist to the awareness of the other physician groups.

\section{Conclusion:-}

We found that there is significant percentage of physicians did not have enough knowledge about Celiac disease that may affect the early detection of the disease and the patients' quality of life negatively and may lead to complications and delay their treatment.

\section{Acknowledgements:-}

We would like to offer our special thanks to prof. Abdulrahman Aljebreenfor his patient guidance, enthusiastic encouragement and useful critiques of this research work and for his willingness to give his time so generously has been very much appreciated. We would also like to extend our thanks to Prof. Shaffi Ahmed and Prof. Ahmed Mandil for encouraging us to develop our research study and for allowing us to grow as a researchers, Their advice on both research as well as on our medical career have been priceless. We would like to think dr.Nazia Sadaf who helped us in analyzing our data her help was of great valve. And finally we would like to acknowledge the support provided by our families' during the preparation of our research.

\section{References:-}

1. Green PH, Jabri B, Coeliac disease. Lancet 2003;362:383-91.

2. West J, Logan RF, Hill PG, et al. Seroprevalence, correlates, and characteristics of undetected coeliac disease in England. Gut 2003;52:960-5.

3. Mäki M, Mustalahti K, Kokkonen J, et al. Prevalence of celiac disease among children in Finland. N Engl J Med 2003;348: 2517-24.

4. Tatar G, Elsurer R, Simsek H, et al. Screening of tissue transglutaminase antibody in healthy blood donors for celiac disease screening in the Turkish population. Dig Dis Sci 2004;49:1479-84.

5. Fasano A, Berti I, Gerarduzzi T, et al. Prevalence of celiac disease in at-risk and not-at-risk groups in the United States: a large multicenter study. Arch Intern Med 2003;163:286-92.

6. Bingley PJ, Williams AJ, Norcross AJ, et al. Undiagnosed coeliac disease at age seven: population based prospective birth cohort study. BMJ 2004;328:322-3.

7. Aljebreen AM, Almadi MA, Alhammad A, Al Faleh FZ. Seroprevalence of celiac among healthy adolesntes in Saudi Arabia. World J Gastroenterol 2013; 19: 2374-8.

8. Riordan FA, Davidson DC. Revised criteria for diagnosis of coeliac disease and medical audit.

9. Arch Dis Child 1991; 66: 561.

10. Rostom A, Murray JA, Kagnoff MF. American Gastroenterological Association (AGA) Institute technical review on the diagnosis and management of celiac disease. Gastroenterology 2006; 131: 1981-2002.

11. 10 - Frost AR, Band MM, Conway GS. Serological screening for coeliac disease in adults with Turner's syndrome: prevalence and clinical significance of endomysium antibody positivity. Eur $\mathrm{J}$ Endocrinol 2009;160:675-9.

12. Sugai E, Vázquez H, Nachman F, et al. Accuracy of testing for antibodies to synthetic gliadinrelated peptides in celiac disease. Clin Gastroenterol Hepatol 2006;4: 1112-7.

13. Rostom A, Dube C, Cranney A, et al. The diagnostic accuracy of serologic tests for celiac disease: a systematic 
review. Gastroenterology 2005;128:Suppl 1:S38-S46.

14. Saadah OI, Al Agha AE, Albokhari SM Al Mughales JA. Screening of Saudi children with short stature for celiac disease. 2nd Word Congress of Paediatric Gastroenterology Hepatology and Nutrition. Paris, 2004: Abstract P0405.

15. Saadah OI, Agha AE, Albokhari SM, Al Mughales JA. Prevalence of celiac disease in Saudi children with type 1 diabetes mellitus. 2nd Word Congress of paediatric Gastroenterology Hepatology and Nutrition. Paris, July 2004. Abstract P0408.

16. Al-Ashwal AA, Shabib SM, Sakati NA, Attia NA. Prevalence and characteristics of celiac disease in type I diabetes mellitus in Saudi Arabia. Saudi Med J 2003; 24: 1113-1115.

17. Peräaho M, Kaukinen K, Mustalahti K, et al. Effect of an oats-containing gluten-free diet on symptoms and quality of life in coeliac disease: a randomized study. Scand J Gastroenterol 2004;39:27- 31.

18. Lee SK, Lo W, Memeo L, Rotterdam H, Green PH. Duodenal histology in patients with celiac disease after treatment with a gluten-free diet. Gastrointest Endosc 2003; 57:187-91.

19. Michael M, Recognizing and managing celiac disease in primary care. J Am Acad Nurse Pract 2003; 15: 10814.

20. Dickey W, McMillan SA, Hughes DF. Identification of coeliac disease in primary care. Scand J Gastroenterol 1998; 33: 491-3.

21. Lanzarotto F, Crimí F, Amato M, Villanacci V, Pillan NM, Lanzini A. Is under diagnosis of celiac disease compounded by mismanagement in the primary care setting?. A survey in the Italian Province of Brescia. Minerva Gatroenterol Dietol 2004; 50: 283-8.

22. Ress K, Harro M, Maaroos HI, Harro J, Uibo R, Uibo O. High prevalence of coeliac disease: need for increasing awareness among physicians. Dig Liver Dis 2007; 39: 136-9.

23. Zipser RD, Farid M, Baisch D, Patel B, Patel D. Physican awareness of celiac disease: A need for further education. J Gen Intern Med. 2005; 20: 644-6. 
Appendices:-

Questionnaire:-

The purpose of this survey is to determine the knowledge and the awareness of the physician about celiac disease. The questionnaire is voluntary and the data collected is strictly confidential.

Name (optional):

Gender: $\square$ Male. $\square$ Female.

Age: $\square 25-30 \quad \square 30-40 \quad \square 40-50 \quad \square>50$

Specialty:

$\square$ Primary Care Physician

q Internal Medicine

$\square$ Gastroenterologist

$\square$ Endocrinologist

$\square$ Hematologist.

$\square$ Pediatrician

Which of the following is the hospital that you work in?

$\square$ king Khalid University Hospital (KKUH).

$\square$ King Abdulaziz university Hospital (KAUH).

$\square$ King Saud Medical City (al-shemaisi).

$\square$ Dallah Hospital.

$\square$ Al-Habeeb Medical centers.

वOther:

Years of practice: $\square<1$ year $\square 1-5 \quad \square 6-10 \quad \square>10$ years

All the questions have one answer, so please pick the one you think is the correct.

1. How many celiac disease patients did you diagnosed in the past 1 year?
$\square<1 \quad \square 1-5$
$\square 5-10$
a10-15
ㅁ $>15$

2. Celiac disease is an intolerance to

$\square$ milk products $\square$ wheat products $\square$ milk, wheat and oats products $\square$ cow milk 미 don't know.

3. Celiac disease affect patients at this age

$\square$ Children $\square$ Adults $\square$ Elderly $\square$ at anyage aldon't know. 


\section{RB approval:-}

4. Celiac disease is common in the west compared to Saudi Arabia?

aYes. aNo. al don't know.

5. Bleeding per rectum is one of the most common symptoms of celiac disease aYes. aNo. al don't know.

6. Which one of the symptoms is not related to celiac disease? $\square$ Shortness of breath $\square$ Depression $\square$ palpitations $\square$ weight loss $\square$ fatigue $\square$ cough 口 I don't know.

7. Which one of the following is not related to celiac disease $\square$ ulcerative colitis $\square$ liver disease asthma aDowns syndrome adiabetes mellitus a hypothyroidism aldon't know.

8. Celiac disease is believed to be highly associated with diabetes typez more than type1. aYes. aNo. al don't know.

9. Which of the following is not a complication of celiac disease? aseizure 口osteoporosis aintestinal lymphoma cinfertility csmall bowel cancer acolon cancer al don't know.

10. Intestinal biopsy is a mandatory test to confirm celiac disease. aYes. aNo. al don't know.

11. The most specific celiac antibody test is: $\square$ Anti-gliadin Antibody (AGA) םAnti-endomysial Antibody (EMA) ם Anti-tissue transglutaminase Antibody (anti-tTG)

12. The blood tests for gluten autoantibodies are accurate only while on a gluten containing diet. aYes. $\square$ No. al don't know.

13. There is no need to do a genetic testing for the family members of a person diagnosed with celiac disease. aYes. aNo. al don't know.

14. The first step in the management of the celiac disease patient is a gluten free diet cimmunosuppression cantibiotics clactose free diet al don't know

15. The damage of small intestine will not be repaired again after the diet aYes. aNo. 미 don't know.

16. The gluten-free diet should be a lifelong diet. aYes. aNo. al don't know. 